\title{
Statistical and Machine Learning Analysis of Impact of Population and Gender Effect in GDP of Bangladesh: A Case Study
}

\author{
Md. Rayhan Ahmed \\ Department of Computer Science and Engineering, Stamford University Bangladesh, Dhaka, Bangladesh \\ E-mail: rayhansimanto@gmail.com \\ Ashfaq Ali Shafin \\ Department of Computer Science and Engineering, Stamford University Bangladesh, Dhaka, Bangladesh \\ E-mail: shafinashfaqali21@gmail.com
}

Received: 07 October 2019; Accepted: 25 October 2019; Published: 08 February 2020

\begin{abstract}
Gross Domestic Product (GDP) per capita is a critical degree of a nation's monetary growth that records for its number of people. A balanced participation ratio of both males and females in the industry by ensuring skilled and technical education for all provides a stable economic development in a country. Population and Gender impact on GDP prices in Bangladesh were investigated in this study. To address the effect of gender factors in GDP prices, we considered the following parameters: year, combined population, male population, and female population. Based on these parameters, the global domestic product-current prices of Bangladesh were analyzed. For the predictive analysis, we have used various machine learning algorithms to make prediction and visualization of the predicted output. A quantitative analysis was also performed to examine the correlation among different gender factors with the growth of GDP. Based on analysis and study results, we can say that the machine learning approach could be applied efficiently in numerous applications of GDP forecasting.
\end{abstract}

Index Terms - GDP, Population, Bangladesh, Machine Learning, Linear Regression, Polynomial Regression, SVR.

\section{INTRODUCTION}

Inconsistent growth of the population is both affected and affects many factors, from economic inequality to degrading social status and the workforce of a nation [1]. Gender equality can have a stimulating effect on both the GDP level and growth rates in a country. In a country ensuring gender equality in education, health, and job sector creates a productive workforce that can lead to a higher GDP level and, perhaps, also the faster the invention process [2]. Due to the modern advancement of knowledge and technology, invention purposes are changed over phase. Population growth is defined as the rise in the number of human residents of a given residence.

The importance of population is decisive since it has substantial bearings on the improvement and progression of a nation. About $50 \%$ of the entire communities of Bangladesh are women. Roughly, $75 \%$ of the population lives in countryside regions. These people establish an imperative section of society and cannot be overlooked. They can contribute a substantial part in the quest for cost-effective development.

A World Bank report published in 2007 stated that the areas in which women's workforce participation has increased the most are in the fields of agriculture, education, and health and social work [3]. Though, in practice, it is observed that women experience very challenging and unfair work conditions, lesser wage payment, less benefit than men do. To enhance our economic progress, the involvement of women in both government and non-government organizations must be given higher priority.

The relationship between population growth and economic progression has been a debatable issue in the field of commercial advancement. History around the world shows that low population growth is associated with moderate economic progress, and high population growth is associated with high economic growth and commercial progression.

GDP is the entire value of every product, properties, or services that are being produced in the country. If any entity provides those items within the country's regional boundaries, their production value is added to that country's GDP.

GDP can be calculated in three ways: value-added approach, expenditure approach, an income approach.

GDP by value-added approach: It sums the outputs of all the classes of the enterprise to arrive at the total.

GDP by income approach: It uses the sum of primary incomes distributed by local producer units.

GDP by expenditure approach: 


$$
G D P=C+I+G+(X-M)
$$

In equation (1), $C=$ Consumption, $I=$ Investment, $G=$ Government Spending, $X=$ Exports, and $M=$ Imports.

The statistical learning approach and quantile loss functions can also be used to correctly predict GDP for a sequence of time series by building confidence intervals [4].

Artificial neural network attained superior outcomes in performance and efficacy compared to orthodox methods in predicting systems [5]. GDP forecast precision was enhanced with development in alteration as well as with the growth in the information realm [6]. GDP growth was measured as a natural-growth procedure receptive to the report by the logistic-growth equation [7]. There is a growing need for GDP rate prediction in terms of the male and female population to decide which gender makes a significant impact on the growth of GDP price rate of Bangladesh and for this, an analysis using machine learning was done to show that which gender has more influence in increasing GDP growth rate of current prices. In our study, we intend to emphasize on the parameters: combined population, male population, the female population over the years from 1980 to 2019 to forecast the future GDP and population in Bangladesh by using machine learning algorithms such as simple linear regression, multi-degree polynomial regression, and support vector regression (SVR).

\section{Methodology}

Many parameters create an impact on current prices of GDP growth. Our study leans towards finding the correlation between population growth, both male and female, and the GDP growth rate of Bangladesh for the period of the year 1980 to 2019. Data have been taken from the Bangladesh Open Data portal (http://data.gov.bd/). The dependent variable considered is Gross Domestic Product growth GDP measure as an annual percentage. In our study of Bangladesh's economic GDP, four factors were selected from our dataset. The first input parameter was the number of years. The second input parameter was the combined population, which includes both male and female genders in each year. The third input parameter was only the number of male genders in each year. The fourth input was only the number of female genders in each year.

From these input parameters, we analyzed the GDPcurrent prices by applying linear regression, multi-degree polynomial regression, and support vector regression (SVR) to analyze, forecast, and predict influencing factors of future economic GDP of Bangladesh.

For the analysis, years, combined population, male population, and female population were taken as input parameters and global domestic product (GDP) current prices were chosen as the output parameter.
Table 1. Input and Output parameters

\begin{tabular}{|c|c|c|}
\hline \multicolumn{2}{|c|}{ Input } & Output \\
\cline { 1 - 2 } Input 1 & Year & \multirow{2}{*}{$\begin{array}{c}\text { GDP: Current } \\
\text { Prices }\end{array}$} \\
\cline { 1 - 2 } Input 2 & Combined population & \\
\hline Input 3 & Male population & \\
\hline Input 4 & Female population & \\
\hline
\end{tabular}

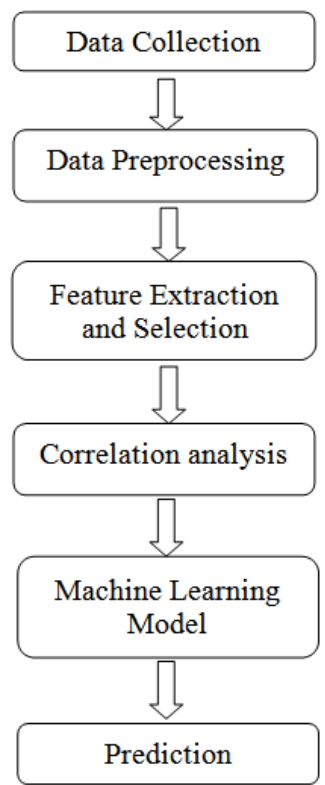

Fig.1. Flow Chart representation of the methodology of the study.

\section{StATISTICAL DATA ANALYSIS \& EXPERIMENT IMPLEMENTATION}

Statistical and Descriptive analysis [8], Correlation checking, Normality distribution of data, Paired Wise T Testing among parameters with respect to the global domestic product was done to analyze the data in an effective way that helped to implement algorithms to our dataset to bring out the satisfactory outcome. Skewness and Kurtosis value in each entity represents the normal distribution and negligible occurrence of outliers in the dataset. A quantitative and descriptive statistical analysis [9] was also performed in SPSS to check the dataset in terms of dispersion and posterior distribution values of experimented data and described in table 2. A normality distribution test was performed in our experimented dataset, Our Sig. value is higher than 0.05. Hence, the rejection of the null hypothesis in our dataset used in the study resulted in a failed state. We have Sig. value of 0.058 in our tests of normality. The normality distribution test was done using the Kolmogorov-Smirnov and Shapiro-Wilk method in SPSS with satisfactory results, as shown in Table 3. Box Plot was also generated to check for outliers in the year, combined population, male, female population. GDP current price, no outliers were found. So, we can state with $95 \%$ confidence that the dataset used for the study was normally distributed. 
From our dataset, we have calculated the mean with the standard error of population, male, female, GDP current price, To compare the means, we have performed Paired Sample T-Test between population-GDP current price, male-GDP current price, and female-GDP current price. From this test, we have analyzed paired samples statistics, paired-samples correlations [10] with a confidence interval level $(\mathrm{CI})=95 \%$.

Paired Sample T-test calculation performed in SPSS are shown in Table 4, 5, and 6 to tests the null hypothesis, the procedure is as follows:

1. Calculate the differences.

$$
\operatorname{diff}_{i}=Y_{i}-X_{i}
$$

Here, $X_{i}$ and $Y_{i}$ are instances of each pair of observations.

2. Calculate the mean difference:

$$
\overline{\operatorname{diff}}=\left(\sum \text { diff }_{i}\right) / n
$$

3. Calculate the standard deviation of the differences:
$S_{\text {diff }}$ and we will use that value to compute the standard error of the mean difference,

$$
S E(\overline{d i f f})=\frac{S_{\text {diff }}}{\sqrt{n}}
$$

4. t-statistic calculation:

$$
T=\frac{\overline{\text { diff }}}{S E \overline{\text { diff })}}
$$

In accordance with the null hypothesis, it follows a tdistribution of $n-1$ degrees of freedom.

5. The t-distribution table is then used to compare the value of $T$ the $t_{n-1}$ distribution, giving us $p$ - value for the Paired t-test.

A descriptive analysis of the dataset is presented in Table 2. Skewness and Kurtosis value in each entity

\begin{tabular}{|c|c|c|c|c|c|c|c|c|c|}
\hline \multicolumn{10}{|c|}{ Descriptive Statistics } \\
\hline & $\mathrm{N}$ & Minimum & Maximum & Mean & Std. Deviation & \multicolumn{2}{|c|}{ Skewness } & \multicolumn{2}{|c|}{ Kurtosis } \\
\hline & Statistic & Statistic & Statistic & Statistic & Statistic & Statistic & $\begin{array}{c}\text { Std. } \\
\text { Error }\end{array}$ & Statistic & $\begin{array}{c}\text { Std. } \\
\text { Error }\end{array}$ \\
\hline Year & 40 & 1980 & 2019 & 1999.50 & 11.690 & 0.000 & 0.374 & -1.200 & 0.733 \\
\hline Population & 40 & 80253062 & 168065920 & 126602576.25 & 26880582.76 & -0.162 & 0.374 & -1.246 & 0.733 \\
\hline Male & 40 & 41581897 & 87080787.72 & 65597189.78 & 13927763.16 & -0.162 & 0.374 & -1.246 & 0.733 \\
\hline Female & 40 & 38671165 & 80985132.28 & 61005386.47 & 12952819.60 & -0.162 & 0.374 & -1.246 & 0.733 \\
\hline $\begin{array}{c}\text { GDP Current } \\
\text { Price } \\
\end{array}$ & 40 & 41.097 & 822.04 & 257.54 & 215.53 & 1.126 & 0.374 & 0.307 & 0.733 \\
\hline
\end{tabular}
represents the normal distribution and negligible occurrence of outliers in the dataset.

Table 2. Descriptive Analysis of the Dataset

Table 3. Test for Normal Distribution

\begin{tabular}{|l|c|c|c|c|c|c|}
\hline \multicolumn{10}{|c|}{ Tests of Normality } \\
\hline & \multicolumn{2}{|c|}{ Kolmogorov-Smirnov ${ }^{\mathrm{a}}$} & \multicolumn{3}{c|}{ Shapiro-Wilk } \\
\cline { 2 - 7 } & Statistic & df & Sig. & Statistic & df & Sig. \\
\hline difference & 0.090 & 40 & $.200^{*}$ & 0.947 & 40 & 0.058 \\
\hline
\end{tabular}

Paired Samples Correlations performed in SPSS between pair 1: combined population - GDP current price, pair 2: male population - GDP current price and pair 3: Female population - GDP current price shows us the Bivariate Pearson Correlation Co-efficient for all the variables entered in each pair which gives us a Sig. (2 tailed - P-value) a value less than 0.05 , as shown in Table 4. There was a significant and positive noteworthy correlation among all the pairs with correlation $r=0.899$ and $P$ value less than 0.05 .

Table 4. Paired Samples Correlations

\begin{tabular}{|c|l|c|c|}
\hline \multicolumn{2}{|l|}{} & Correlation & Sig. \\
\hline Pair 1 & Population \& GDP Current Price & 0.899 & 0.000 \\
\hline Pair 2 & Male \& GDP Current Price & 0.899 & 0.000 \\
\hline Pair 3 & Female \& GDP Current Price & 0.899 & 0.000 \\
\hline
\end{tabular}


Table 5. Paired Samples Statistics

\begin{tabular}{|c|c|c|c|c|}
\hline \multicolumn{2}{|c|}{ Pairs } & Mean & Std. Deviation & Std. Error Mean \\
\hline \multirow{2}{*}{ Pair 1 } & Population & 126602576.25 & 26880582.76 & 4250193.32 \\
\cline { 2 - 5 } & GDP Current Price & 257.54 & 215.53 & 34.08 \\
\hline \multirow{3}{*}{ Pair 2 } & Male & 65597189.78 & 13927763.16 & 2202172.72 \\
\cline { 2 - 5 } & GDP Current Price & 257.54 & 215.53 & 34.08 \\
\hline \multirow{2}{*}{ Pair 3 } & Female & 61005386.47 & 12952819.60 & 2048020.60 \\
\cline { 2 - 5 } & GDP Current Price & 257.54 & 215.53 & 34.08 \\
\hline
\end{tabular}

Table 6. Paired Samples Test

\begin{tabular}{|c|c|c|c|c|c|c|c|c|c|}
\hline & \multirow{3}{*}{ Pairs } & \multicolumn{5}{|c|}{ Paired Differences } & \multirow{3}{*}{$\begin{array}{l}\text { t-statistic } \\
(\mathrm{t})\end{array}$} & \multirow{3}{*}{$\begin{array}{l}\text { Degrees of } \\
\text { freedom } \\
\text { (df) }\end{array}$} & \multirow{3}{*}{$\begin{array}{l}\text { Sig. (2- } \\
\text { tailed) }\end{array}$} \\
\hline & & \multirow{2}{*}{ Mean } & \multirow{2}{*}{ Std. Deviation } & \multirow{2}{*}{$\begin{array}{l}\text { Std. Error } \\
\text { Mean }\end{array}$} & \multicolumn{2}{|c|}{$\begin{array}{l}\text { 95\% Confidence Interval of the } \\
\text { Difference }\end{array}$} & & & \\
\hline & & & & & Lower & Upper & & & \\
\hline Pair1 & $\begin{array}{c}\text { Population - } \\
\text { GDP Current } \\
\text { Price } \\
\end{array}$ & 126602318.7 & 26880388.9 & 4250162.7 & 118005553.3 & 135199084.1 & 29.788 & 39 & 0.000 \\
\hline Pair2 & $\begin{array}{l}\text { Male - GDP } \\
\text { Current Price }\end{array}$ & 65596932.2 & 13927569.3 & 2202142.1 & 61142679.5 & 70051184.9 & 29.788 & 39 & 0.000 \\
\hline Pair3 & $\begin{array}{c}\text { Female - GDP } \\
\text { Current Price }\end{array}$ & 61005128.9 & 12952625.8 & 2047989.9 & 56862678.2 & 65147579.6 & 29.788 & 39 & 0.000 \\
\hline
\end{tabular}

Values in Table 6 computed in SPSS, gives us the hypothesis test results using the following hypothesis presented in equation (6) and (7),

$$
\begin{aligned}
& \text { HYPOTHESIS }_{1}: \mu_{1}-\mu_{2}=0 \\
& \text { HYPOTHESIS }_{2}: \mu_{1}-\mu_{2} \neq 0
\end{aligned}
$$

Here, $\mu_{1}$ and $\mu_{2}$ represent the mean of variables one and two in each pair, respectively.

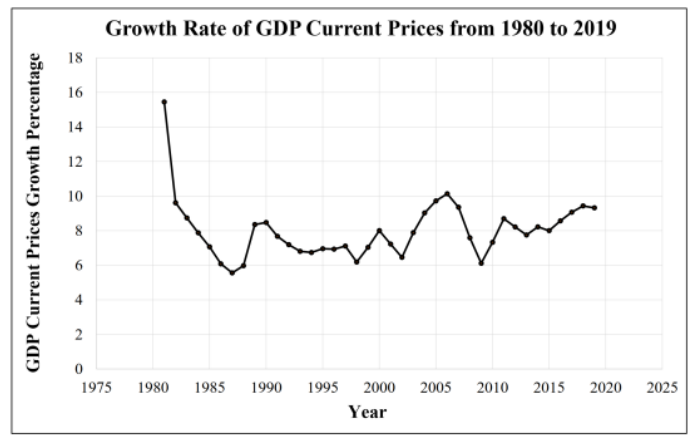

Fig.2. Visualization of the Growth Rate of the current price of with respect to years from 1980 to 2019.

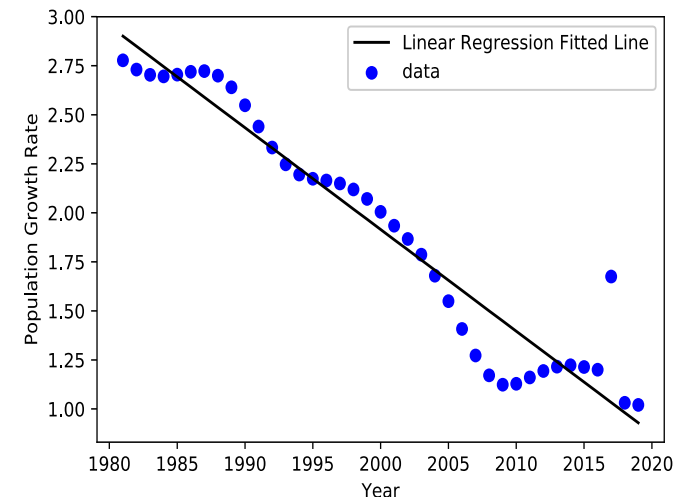

Fig.3. The growth rate of the population in Bangladesh is shown here. The graph shows the growth rate of people has decreased in the last 40 years in Bangladesh.

There is a significant difference between the mean of variables in each tested pair. We see that our Sig. the value doesn't fall between the lower and upper ranges of any pairs. Since the Sig. value is 0.000 ; we can reject the null hypothesis [11]. Here, test statistic, $t$ with $\mathrm{df}=39$ degrees' freedom equals 29.788 , and the p-value is less than 0.005 . 


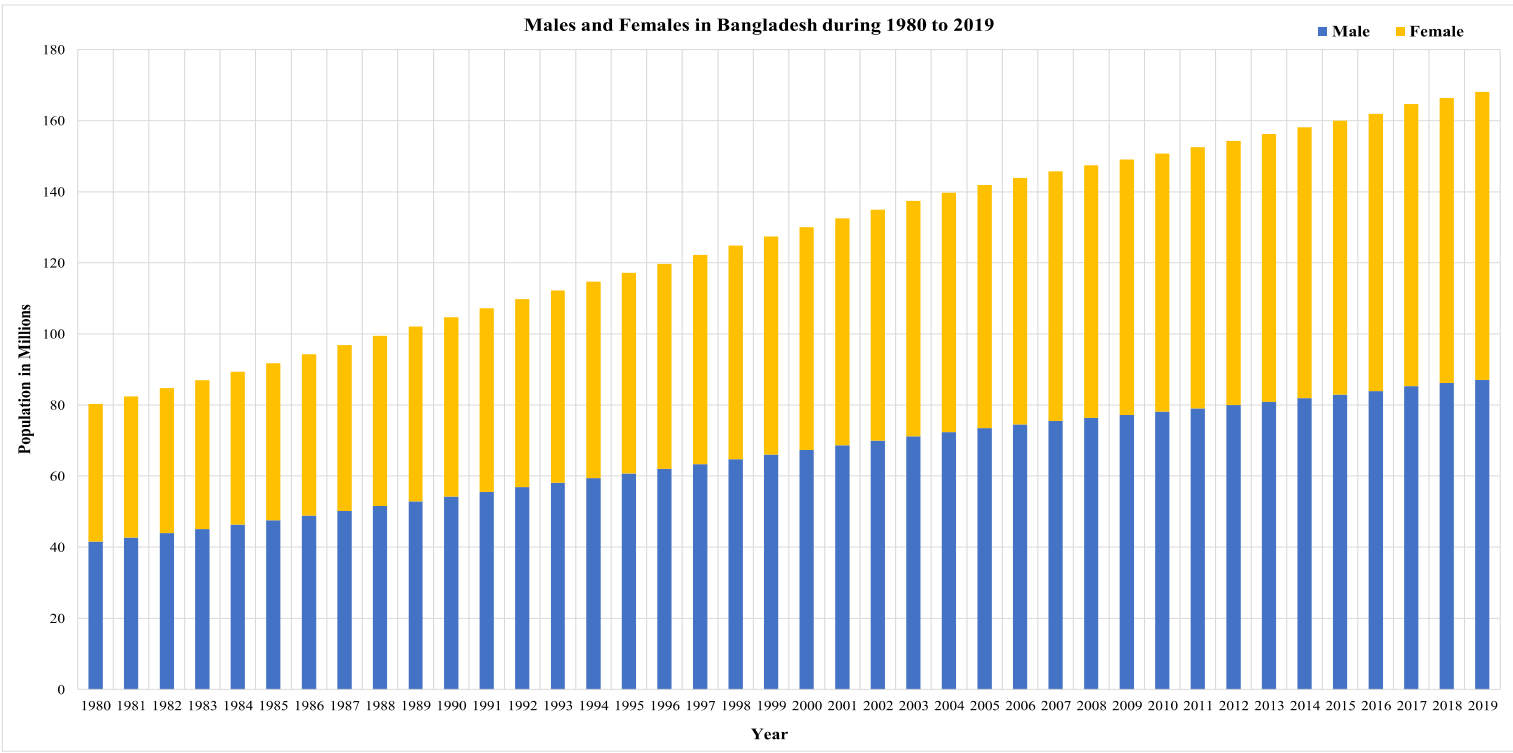

Fig.4. The number of male and female population in Bangladesh between the periods of 1980 to 2019 in millions is presented here. In 2019, the graph illustrates that the female population is around $49.5 \%$, and the male population is about $50.5 \%$ of the total population in Bangladesh.

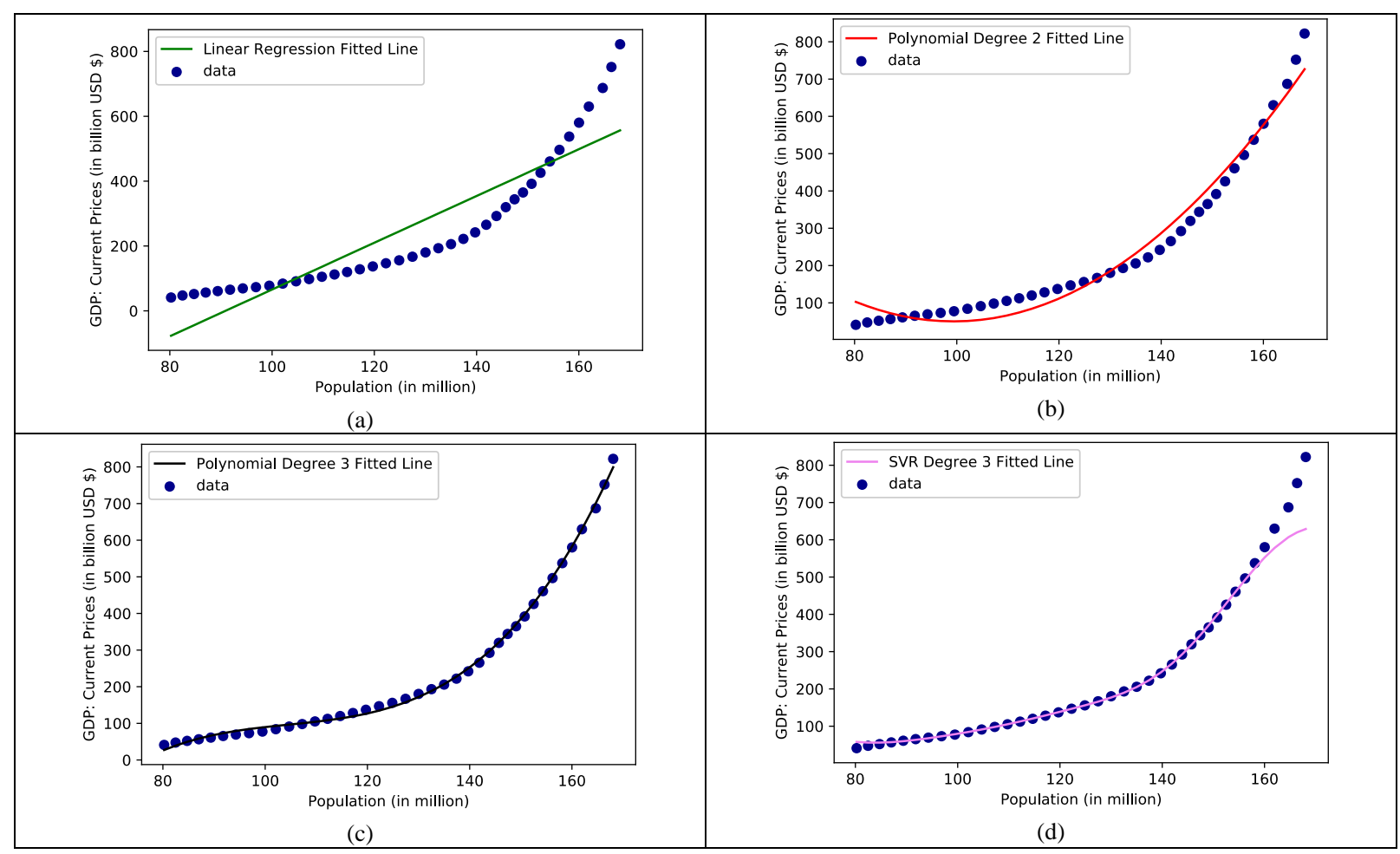

Fig.5. The current price of GDP (in billion USD \$) with respect to Population (in a million). 5-(a) Visualization of simple linear regression. 5-(b) Polynomial regression using the second degree was used here because of the non-linear characteristics of our dependent variable (GDP) and independent variable (Population). 5-(c) Polynomial regression using third degree was used here because of the non-linear characteristics of our dependent variable (GDP) and independent variable (Population). 5-(d) Support Vector Regression (SVR) algorithm was used here for the comparative analysis. 


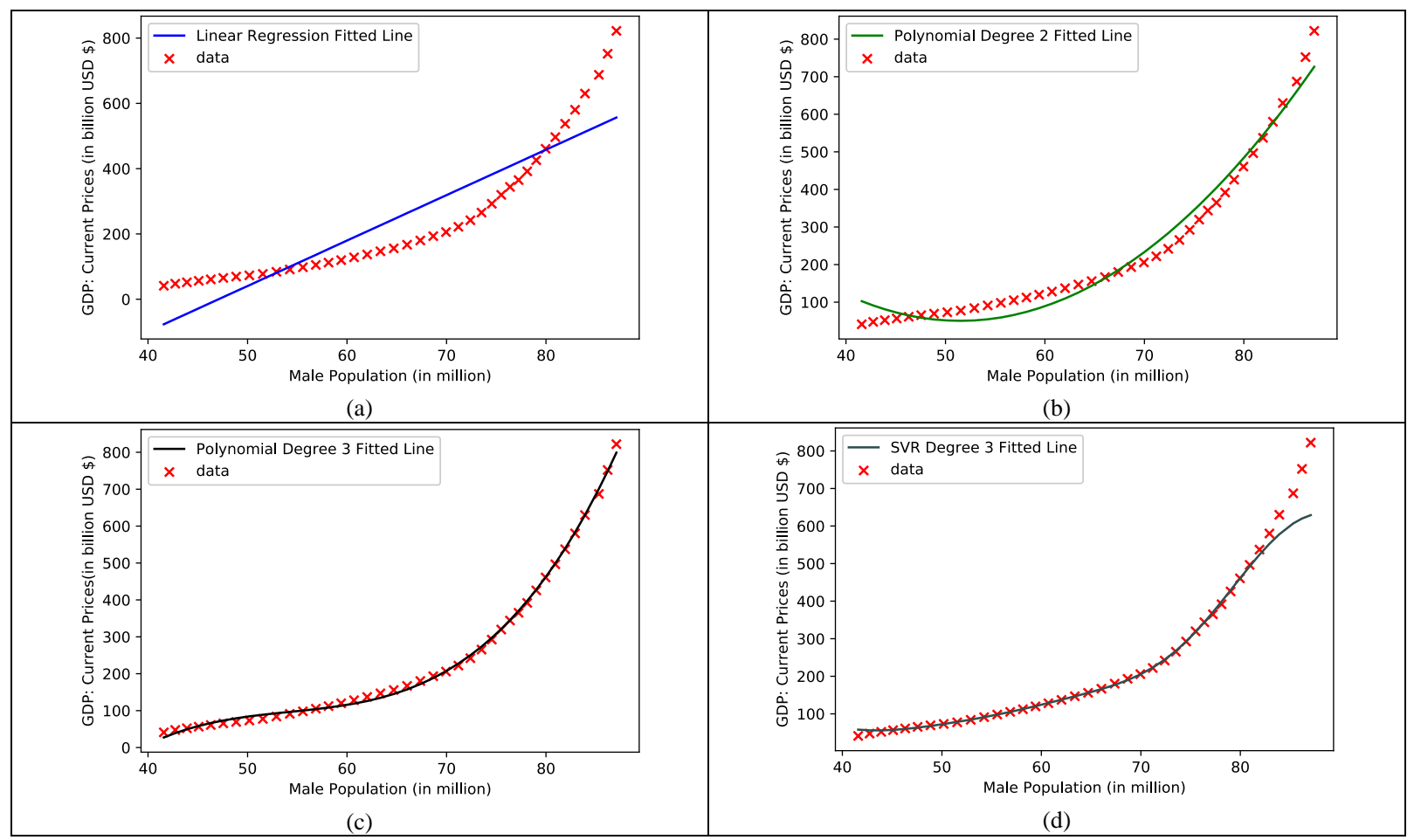

Fig.6. The current price of GDP (in billion USD \$) with respect to Male-Population (in a million). 6-(a) Visualization of simple linear regression. 6(b) Polynomial regression using the second degree was used here because of the non-linear characteristics of our dependent variable (GDP) and independent variable (Male-Population). 6-(c) Polynomial regression using a third-degree was used here because of the non-linear characteristics of our dependent variable (GDP) and independent variable (Male-Population). 6-(d) Support Vector Regression (SVR) algorithm was used here for the comparative analysis

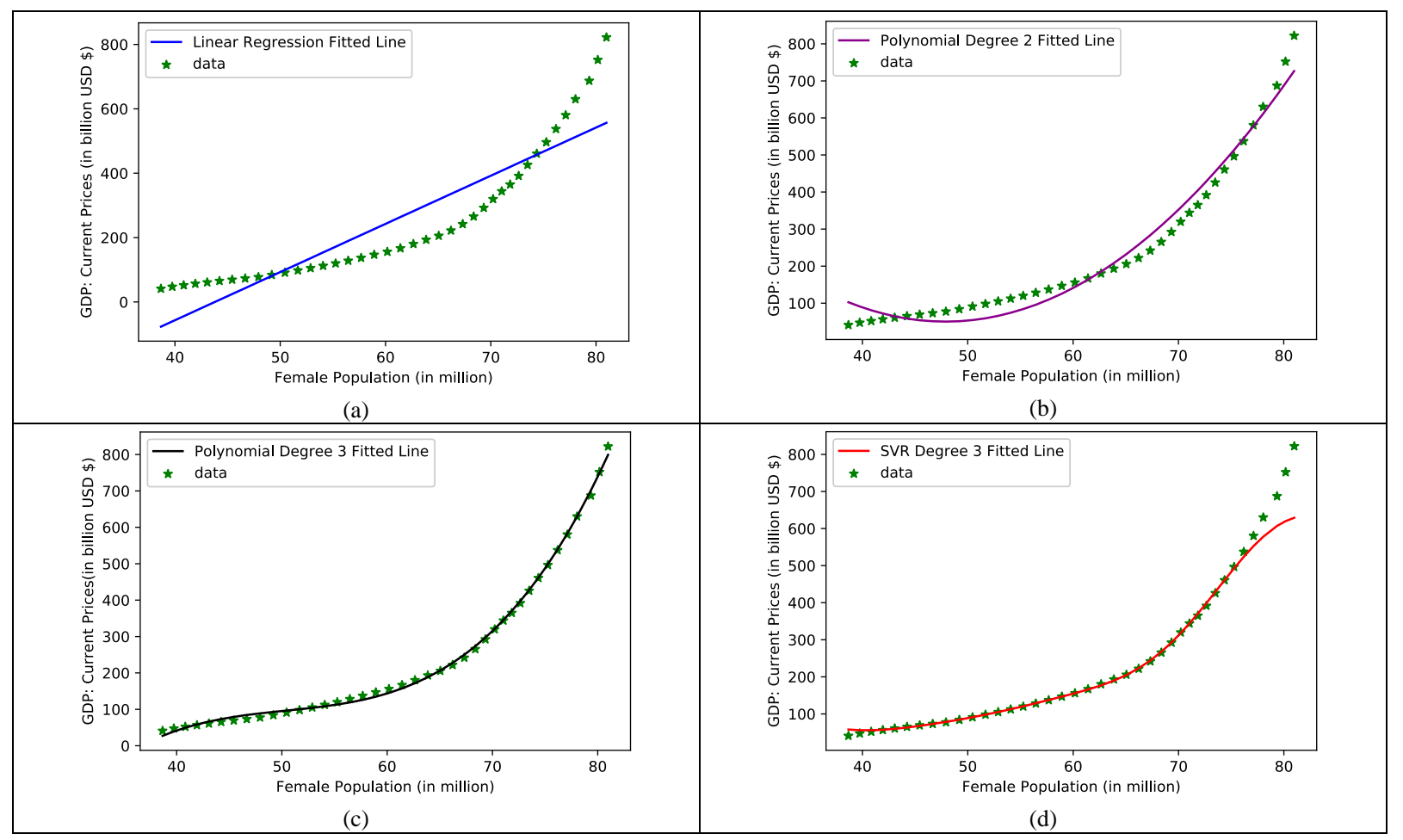

Fig.7. The current price of GDP (in billion USD \$) with respect to Female-Population (in a million). 7-(a) Visualization of simple linear regression. 7-

(b) Polynomial regression using the second degree was used here because of the non-linear characteristics of our dependent variable (GDP) and independent variable (Female-Population). 7-(c) Polynomial regression using a third-degree was used here because of the non-linear characteristics of our dependent variable (GDP) and independent variable (Female-Population). 7-(d) Support Vector Regression (SVR) algorithm was used here for the comparative analysis. 


\section{SUMMARY OF THE EXPERIMENT RESULT}

From our study, we have examined the growth rate of population and GDP. Simple linear regression [12], polynomial regression [13] of degree 2 and 3, support vector regression algorithms $[14,15]$ were used for the prediction. Among those algorithms polynomial regression, degree 3 yields the best accuracy in prediction with an accuracy of $99.86 \%$ in terms of combined population, $99.85 \%$ in terms of both male and female population, as shown in Tables 7,8 , and 9. These tables show the accuracy of different machine learning algorithms in our dataset. Statistical analysis was also implemented in our dataset to find a correlation between those factors for current GDP prices. We have also predicted the future combined population, male and female population from the year 2020 to the year 2035 in Bangladesh.

It can be inferred that the population is highly correlated to the GDP: Current Prices of Bangladesh and the prediction accuracy is over $99 \%$ accurate in these findings when the polynomial regression of degree 3 is employed in the system. The lowest accuracy is achieved by linear regression, which yields accuracy of over $80 \%$ in all the cases.

Table 7. GDP Prediction-Experiment Result (Parameter: Population)

\begin{tabular}{|c|c|c|}
\hline Feature & Algorithm & $\begin{array}{c}\text { Prediction } \\
\text { Accuracy }\end{array}$ \\
\hline Population & Linear Regression & $80.88 \%$ \\
\hline Population & Polynomial Regression 3 & $99.86 \%$ \\
\hline Population & Polynomial Regression 2 & $97.37 \%$ \\
\hline Population & SVR Polynomial 3 & $96.39 \%$ \\
\hline
\end{tabular}

Table 8. GDP Prediction-Experiment Result (Parameter: Male)

\begin{tabular}{|l|c|c|}
\hline Feature & Algorithm & $\begin{array}{c}\text { Prediction } \\
\text { Accuracy }\end{array}$ \\
\hline Male & Linear Regression & $80.88 \%$ \\
\hline Male & Polynomial Regression 3 & $99.85 \%$ \\
\hline Male & Polynomial Regression 2 & $97.38 \%$ \\
\hline Male & SVM Polynomial 3 & $96.40 \%$ \\
\hline
\end{tabular}

Table 9. GDP Prediction-Experiment Result (Parameter: Female)

\begin{tabular}{|c|c|c|}
\hline Feature & Algorithm & $\begin{array}{c}\text { Prediction } \\
\text { Accuracy }\end{array}$ \\
\hline Female & Linear Regression & $80.88 \%$ \\
\hline Female & Polynomial Regression 3 & $99.85 \%$ \\
\hline Female & Polynomial Regression 2 & $97.37 \%$ \\
\hline Female & SVR Polynomial 3 & $96.39 \%$ \\
\hline
\end{tabular}

\section{PREDICTION}

Prediction of GDP is an integral part of economic stability in a country like Bangladesh, where development is booming in the last 20 years. Though it might work for a short term process, to avoid recession in the long term, we need to predict a country's GDP growth rate precisely. After performing detail statistical investigation of our experimental dataset and by applying
Simple Linear Regression with an accuracy of $80.88 \%$, Polynomial Regression Degree 2 with an accuracy of 97.37\%, Polynomial Regression Degree 3 with an accuracy of $99.86 \%$ and Support Vector Regression with an accuracy of $96.40 \%$ in predicting GDP as output parameter and number of combined population, male population and female population as input parameter we see that Polynomial Regression Degree 3 achieves the highest accuracy in predicting GDP based on all the input parameters. Hence for the final prediction chart of combined population, male population, female population, and GDP current prices (in Billions USD \$) from the year 2020 to 2035 in Bangladesh Polynomial Regression Degree 3 was selected. Predicted values are provided as a chart in Table 10.

Figure 8 shows the predicted GDP price for Bangladesh from the year 2020 to 2035 using the Polynomial Regression of degree-3. Figure 9, visualizes the Population prediction utilizing Polynomial Regression of degree-3 from the year of 2020 to 2035. Figures 10 and 11 , are used to depict the Male Population prediction and Female Population prediction for future analysis. We deployed the Polynomial Regression of degree-3 for prediction as it yields the best accuracy rate of over $99 \%$ for all the cases. We did not generate any figures using other machine learning algorithms as they were less accurate in their predictions.

For predicting Population, Male Population, and Female Population, we have deployed a linear regression model that yields $99.56 \%$ accuracy on the training dataset. The equation for the model is given in equation (8). We used the year as the input feature to predict the output population.

$$
\text { predicted_population }=W_{p 0}+\left(W_{p 1} * \text { Year }\right)
$$

predicted_male_population $=W_{m o}+\left(W_{m 1} *\right.$ Year $)$

predicted_femal_population $=W_{f o}+\left(W_{f} 1 *\right.$ Year $)$

From our training dataset, the weight vector for $W_{p 0}$ is equal to -4460.86517621 , and $\mathrm{W}_{p l}$ is equal to 2.29430745 For example, the population (in million) for the year 2022 will be:

predicted_population $(2022)=-4460.86517621+(2.29430745 * 2022)$

predicted_population $(2022)=178.2244939$

For the male population equation (9), $W_{m 0}$ and $W_{m l}$ are equal to $9.27954801 \mathrm{e}-07$ and 1.92999998 , respectively. For the female population equation (10), $W_{f 0}$ and $W_{f l}$ are equal to $9.27953702 \mathrm{e}-07$ and 1.92988879 respectively.

$$
\begin{aligned}
\text { predicted_GDP_CurrentPrice } & =W_{g}+\left(W_{g 1} * P P\right)+\left(W_{g 2} * P P^{2}\right) \\
& +\left(W_{g 3} * P P^{3}\right)
\end{aligned}
$$

Equation (11), is used to predict the GDP:Current Prices where $P P$ indicates the Predicted Population and 
$W_{g}, W_{g 1}, W_{g 2}$, and $W_{g 3}$ represent the weight values. From the training dataset, the values are -2800.45451155 , $80.2326575,-0.0753312699,0.00240000133$ respectively. To calculate the predicted_GDP_CurrentPrice, we implemented the polynomial regression of degree 3 in our dataset which yields $99.86 \%$ accuracy in the training dataset. For example, to predict the GDP of the year 2022 (in billion USD \$):

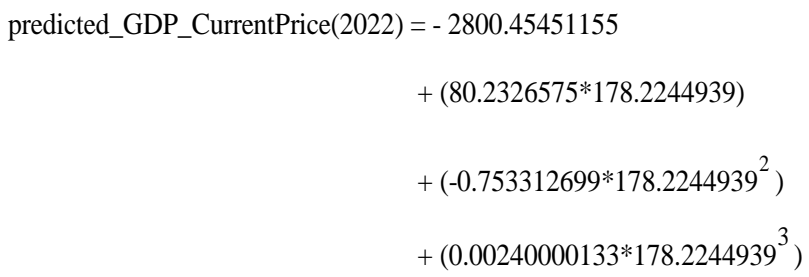

predicted_GDP_CurrentPrice(2022)=1157.4

Table 10. Prediction Chart

\begin{tabular}{|c|c|c|c|c|}
\hline Year & Population & Male & Female & $\begin{array}{c}\text { GDP: } \\
\text { Current Price (in Billion USD \$) }\end{array}$ \\
\hline 2020 & 173635879.0 & 88554298.3 & 85081580.7 & 982.93 \\
\hline 2021 & 175930186.5 & 89724395.1 & 86205791.4 & 1067.4 \\
\hline 2022 & 178224493.9 & 90894491.9 & 87330002.0 & 1157.4 \\
\hline 2023 & 180518801.4 & 92064588.7 & 88454212.7 & 1253.0 \\
\hline 2024 & 182813108.9 & 93234685.5 & 89578423.3 & 1354.3 \\
\hline 2025 & 185107416.3 & 94404782.3 & 90702633.9 & 1461.5 \\
\hline 2026 & 187401723.8 & 95574879.1 & 91826844.6 & 1574.8 \\
\hline 2027 & 189696031.2 & 96744975.9 & 92951055.3 & 1694.4 \\
\hline 2028 & 191990338.7 & 97915072.7 & 94075265.9 & 1820.4 \\
\hline 2029 & 194284646.1 & 99085169.5 & 95199476.6 & 1953.2 \\
\hline 2030 & 196578953.6 & 100255266.3 & 96323687.2 & 2092.6 \\
\hline 2031 & 198873261.0 & 101425363.1 & 97447897.9 & 2239.1 \\
\hline 2032 & 201167568.5 & 102595459.9 & 98572108.5 & 2392.6 \\
\hline 2033 & 203461875.9 & 103765556.7 & 99696319.21 & 2553.5 \\
\hline 2034 & 205756183.4 & 104935653.5 & 100820529.9 & 2721.9 \\
\hline 2035 & 208050490.8 & 106105750.3 & 101944740.5 & 2897.9 \\
\hline
\end{tabular}

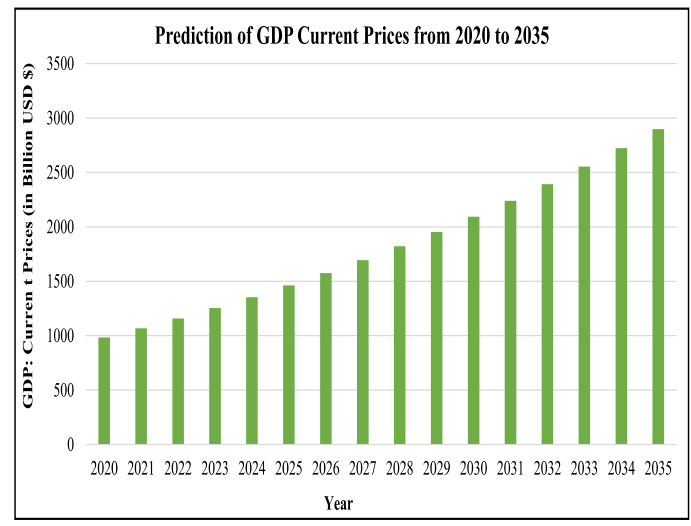

Fig.8. Visual representation of the predicted findings of the study using the Polynomial Regression Degree 3 algorithm about the increase in the current price of GDP from the year 2020 to 2035. From the figure, we see that in 2020 GDP current price will be around 1000 billion USD \$. In 2035, Bangladesh's GDP will be almost triple the GDP of 2020, with approximately 2900 billion USD \$.

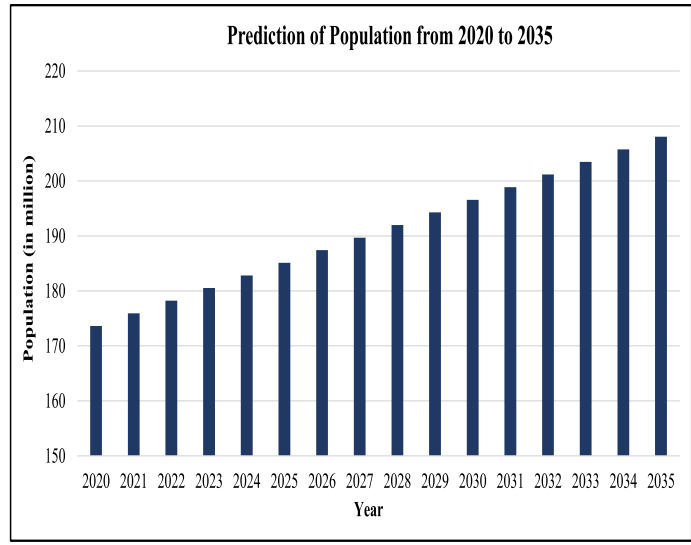

Fig.9. Visual representation of the predicted findings of the study using the Polynomial Regression Degree 3 algorithm about the increase in the population in Bangladesh from the year 2020 to 2035. From the figure, we see that in 2020, the population will be around 174 million. In 2035, Bangladesh's Population will be almost 209 million, with an increase of about 35 million in just 15 years. 


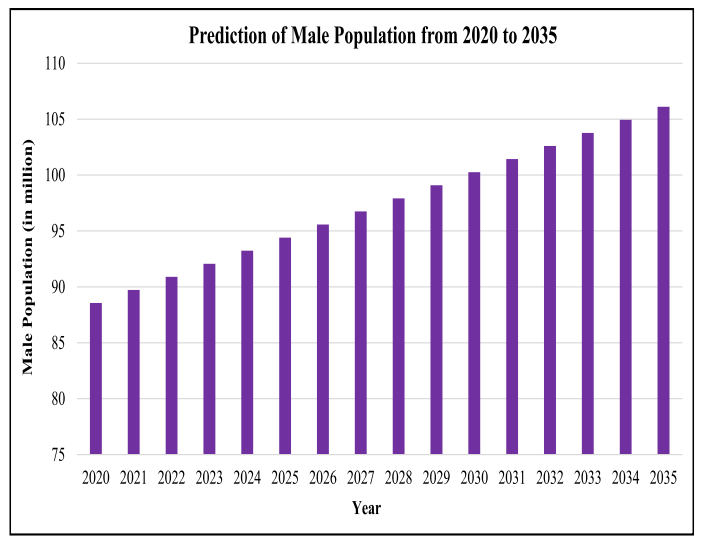

Fig.10. Visual representation of the predicted findings of the study using the Polynomial Regression Degree 3 algorithm about the increase in the male population in Bangladesh from the year 2020 to 2035. From the figure, we see that in 2020, the male population will be around 88 million. In 2035, Bangladesh's male population will be almost 106 million, with an increase of about 18 million in just 15 years.

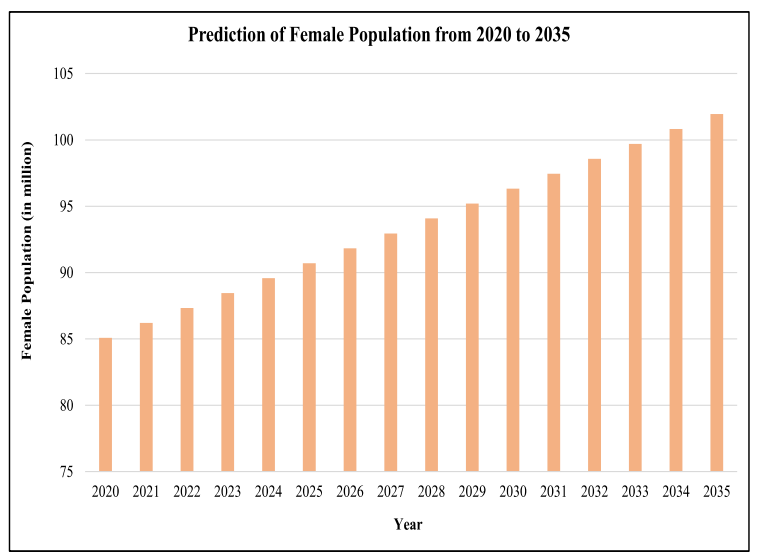

Fig.11. Visual representation of the predicted findings of the study using the Polynomial Regression Degree 3 algorithm about the increase in the female population in Bangladesh from the year 2020 to 2035. From the figure, we see that in 2020 , the female population will be around 85 million. In 2035, Bangladesh's female population will be almost 102 million, with an increase of about 17 million in just 15 years.

\section{CONCLUSION}

In a densely populated country like Bangladesh, combining with reduced literacy rates and a troubled economy, an increase in population will not create a significant, meaningful impact on GDP growth. We have analyzed the GDP increase of current prices in terms of both male and female populations in our study. From the analysis, we state that the present and future GDP of Bangladesh clearly depends on both male and female genders in equal proportion according to our result provided in Tables 9 and 10 with almost the same accuracy levels in predicting GDP. We have predicted the GDP current price of Bangladesh using multiple machine learning algorithms from the year 2020 to 2035 . We have predicted the combined population, male and female population individually in that period too. From our results, we can state that the escalation of the female population cannot be ignored in a country like
Bangladesh to facilitate the economy of this country. According to our prediction of GDP, the impact of female education, workplace improvement, and facilities cannot be unheeded anymore. To create a meaningful GDP in Bangladesh, both male and female populations must work collectively to increase the economic growth of Bangladesh. However, the growth rate has decreased in the last forty years in Bangladesh, but the increase in population is very alarming. That increasing population must be provided an environment that will be beneficial to the social and economic development of Bangladesh. In the future work, many different parameters such as national income, sales taxes, foreign factor income, depreciation, exports, imports, consumption rate can be taken into account with the population to predict GDP more accurately.

\section{REFERENCES}

[1] Peterson, E. Wesley F. "The Role of Population in Economic Growth.” SAGE Open, Oct. 2017, doi:10.1177/2158244017736094.

[2] Löfström, Åsa. "Gender equality, economic growth, and employment." Swedish Ministry of Integration and Gender Equality (2009).

[3] "Whispers to Voices: Gender and Social Transformation in Bangladesh" (PDF). Bangladesh Development Series, Paper No. 22. Washington, D.C.: The World Bank. p. 57.

[4] Alquier, P., \& Li, X. (2012, October). "Prediction of quantiles by statistical learning and application to GDP forecasting." International Conference on Discovery Science (pp. 22-36). Springer, Berlin, Heidelberg.

[5] Linhua Feng, Jianzhen Zhang, "Application of artificial neural networks in tendency forecasting of economic growth." Economic Modelling 40 (2014) 76-80.

[6] Libor Krkoska, Utku Teksoz, "Accuracy of GDP growth forecast for transitions countries: Ten years of forecasting assessed." International Journal of Forecasting 23 (2007) 29-45.

[7] Theodore Modis, "Long Term GDP forecast and prospects for growth." Technological Forecasting \& Social Change 80 (2013) $1557-1562$.

[8] Hastie T., Tibshirani, R., Friedman, J., \& Franklin, J. "The elements of statistical learning: data mining, inference, and prediction." The Mathematical Intelligencer (2005), 27(2), 83-85.

[9] Nardi, Peter M. "Doing survey research: A guide to quantitative methods." Routledge, 2018.

[10] Ross, A., \& Willson, V. L "Paired samples T-test. Basic and advanced statistical tests." (2017). (pp. 17-19). Brill Sense.

[11] Levine, Timothy R., et al. "A critical assessment of null hypothesis significance testing in quantitative communication research." Human Communication Research 34.2 (2008): 171-187.

[12] Narula, Subhash C., and John F. Wellington. "Prediction, linear regression, and the minimum sum of relative errors." Technometrics 19.2 (1977): 185-190.

[13] Ostertagová, Eva. "Modelling using polynomial regression." Procedia Engineering 48 (2012): 500-506.

[14] Basak, Debasish, Srimanta Pal, and Dipak Chandra Patranabis. "Support vector regression." Neural Information Processing-Letters and Reviews 11.10 (2007):203-224.

[15] Yang, Haiqin, et al. "Localized support vector regression 
for time series prediction." Neurocomputing 72.10-12 (2009): 2659-2669.

\section{Authors' Profiles}

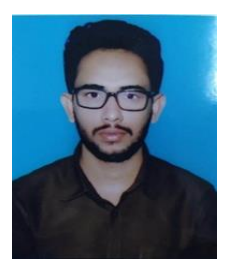

Md. Rayhan Ahmed is currently serving as a Senior Lecturer in the Department of Computer Science and Engineering at Stamford University Bangladesh. $\mathrm{He}$ received his Bachelor of Science degree from Ahsanullah University of Science and Technology in 2014. He is pursuing his Master of Science degree at United International University, Bangladesh. His research interest is Machine Learning, Artificial Neural Network, Computer Vision, and the Internet of Things.

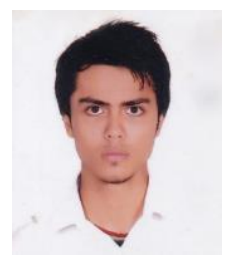

Ashfaq Ali Shafin is currently serving as a Lecturer for the Department of Computer Science and Engineering at Stamford University Bangladesh. In the year of 2018, he completed his Bachelor's degree in Computer Science and Engineering from Ahsanullah University of Science and Technology, securing the second position in a class of 112 students. Currently, he is exploring the research fields of Machine Learning, Natural Language Processing, and Digital Image processing and Computer Vision.

How to cite this paper: Rayhan Ahmed, Ashfaq Ali Shafin, "Statistical and Machine Learning Analysis of Impact of Population and Gender Effect in GDP of Bangladesh: A Case Study", International Journal of Information Technology and Computer Science(IJITCS), Vol.12, No.1, pp.24-33, 2020. DOI: 10.5815/ijitcs.2020.01.04 